\title{
Research on the Current Situation and Teaching Strategies of "Digital Learning and Innovation" Literacy of Senior High School Students
}

\author{
Xinru Yang ${ }^{*}$ and Yigang Ding \\ School of Educational Information Technology, South China Normal University, Guangzhou, China
}

\begin{abstract}
With the development of the digital age, "digital learning and innovation" is becoming more and more important in the core literacy of information technology discipline. Through the elaboration of relevant concepts, this paper explores the connotation and concrete performance of "digital learning and innovation" literacy of senior high school students, and then obtains its three manifestations: the collection and management of digital learning resources, the adaptation of digital environment, the application and innovation of digital learning resources. On this basis, a questionnaire survey was designed to understand the status of "digital learning and innovation" literacy of high school students in S Middle School of Anhui Province, and the data results were analysed. It was found that senior high school students generally have this literacy, but some students still have some problems and need teachers' timely guidance. Therefore, this study further proposes strategies for achieving high school students' "digital learning and innovation" literacy to assist teachers in reminding students of "digital learning and innovation literacy" in teaching.
\end{abstract}

\section{Introduction}

In the digital age, the modernization and informationization of education have become the new requirements of the new curriculum reform. At the same time, the cultivation of "comprehensive development of a complete person" has also become a new requirement of "quality education", and the cultivation of Chinese students' core qualities has been paid attention to. "Ordinary high school information technology curriculum standard" (2017) pointed out that the core accomplishment of training students' information technology disciplines, as information technology courses teaching the subject overall goal, including four parts, respectively is: the "computing thinking", "information consciousness", "social responsibility" and "digital learning and innovation". Pan believes that cultivating students' digital learning and innovation ability is an important part of improving information technology literacy, and also a bridge between the information society and students [1].

Lin proposed that the design of digital learning teaching activities is the key issue of information technology integrated education. The adoption of appropriate teaching

\footnotetext{
* Corresponding author: yang_xinru@126.com
} 
strategies in information technology teaching is conducive to deepening students' awareness and understanding of this accomplishment, and thus cultivating their "digital learning and innovation" accomplishment [2].Yang explored the specific methods of "digital learning and innovation" literacy in the course of subject teaching and studied the implementation of "digital learning and innovation" literacy in subject courses as a whole [3]. Chen proposed the framework and practice research (as well as the integration of information technology and curriculum) for the learning activities of this accomplishment [4]. Francis studied Current trends in digital Learning and innovation [5]. Liu improved the design and innovation ability of high school students through project-based learning [6]. Lankester is committed to improving the digital participation of the community [7]. However, there is a lack of strategy research to achieve this accomplishment by means of high school information technology teaching. The subject of information technology shoulders the important responsibility and mission of cultivating students' core literacy, so it is very necessary to study the strategies to achieve "digital learning and innovation" literacy in the teaching of information technology.

The questionnaire of this study aims to understand the level of literacy of current high school students in the aspect of "digital learning and innovation". The author uses the software "Questionnaire Star" to make a questionnaire on "current situation of digital learning and innovation literacy of senior High school students", and conducts a survey for senior high school students. It is used to explore the strategies to achieve "digital learning and innovation" literacy of high school students, and to assist the teaching of high school information technology courses.

\section{2 "Digital Learning and innovation literacy"}

In the new round of curriculum reform, it can be found that the overall goal of China's basic education has been implemented on the basis of "students' core quality development". Xie believe that discipline core accomplishment is formed in the learning process of knowledge in a certain field or specific discipline, is a necessary character and key ability, reflects the thinking characteristics and attitude of information technology, and is needed for students to adapt to their lifelong development and social development [8]. Specifically, it includes four aspects: "digital learning and innovation", "information awareness", "computational thinking" and "information social responsibility".

"Digital learning and innovation" literacy is an important part of the core of the information technology curriculum literacy, refers to the individual to common digital resources and tools to evaluate and choose, so as to effectively manage the learning process and resource, creatively to solve some problems, tasks, and form a kind of ability of innovative work [9]. Cultivating this literacy requires thinking about the relationship between people and technology, and making use of digital learning environment and resources, so as to help learners construct their own knowledge system under the digital background and environment.

According to the information Technology Curriculum Standard of General High School revised in 2017, cultivating the literacy of "digital learning and innovation" should "understand the advantages and disadvantages of digital learning environment, adapt to the digital learning environment, and develop digital learning habits and innovation habits; Master certain skills, such as the operation skills of digital learning resources, tools and systems, and be able to carry out some innovative, autonomous, shareable and collaborative activities" [9].

At the same time, according to "the ordinary high school information technology curriculum standard" (2017) to discipline the core accomplishment of this paper, the digital learning and innovation quality embodied in three aspects, namely can digital learning 
resources collection and management, to create digital learning environment and application and innovation of digital learning resources. Based on the requirements and connotations of digital learning and innovation literacy, this paper divides its representation into adapting to the digital learning environment, collecting and managing digital learning resources, and applying and innovating digital learning resources.

\section{Research Methods}

In order to intuitively understand the status quo of high school students' "digital learning and innovation literacy", this study selected two classes of S high school in Anhui province as data sources, adopted the questionnaire survey method, designed and issued questionnaires according to the concept and representation of this literacy, and analysed the collected data. Later, according to the development needs of students, literature research method is adopted to consult relevant literature, and the corresponding teaching strategies are put forward on the theoretical basis.

\subsection{Preparation of questionnaire}

To develop a scientific and reasonable questionnaire, we need to start from the elements of "digital learning and innovation" literacy. Based on relevant literature and the 2017 edition of Information Technology Curriculum Standards for Ordinary High Schools, we divided this literacy into three dimensions: "Adaptability to digital environment", "collection and management of digital learning resources", "application and innovation of digital learning resources". The questionnaire consists of "single choice + multiple choice + specific gravity", with a total of 17 questions. The specific composition structure of the questionnaire is shown in the following table (Specific questionnaire in this link: https://www.wjx.cn/jq/70818543.aspx, if there is a need to look at it. ) :

Table 1. Composition of the questionnaire on the status of "digital learning and innovation literacy" among senior high school students.

\begin{tabular}{|c|c|c|c|}
\hline \multirow[t]{2}{*}{ Questionnaire Composition } & \multicolumn{2}{|c|}{ Dimension Division } & \multirow{2}{*}{$\begin{array}{c}\begin{array}{c}\text { Question } \\
\text { Number }\end{array} \\
1,2\end{array}$} \\
\hline & Gender & Grade & \\
\hline \multirow[t]{2}{*}{ Adaptation Of Digital Environment } & Contact Time & Contact Place & 3,4 \\
\hline & $\begin{array}{l}\text { Computer } \\
\text { Applications }\end{array}$ & & 5 \\
\hline \multirow[t]{3}{*}{$\begin{array}{c}\text { Digital Learning Resource Collection } \\
\text { And Management }\end{array}$} & $\begin{array}{l}\text { Technology } \\
\text { Application }\end{array}$ & Tool Use & $6 、 7$ \\
\hline & Search Information & $\begin{array}{l}\text { Processing } \\
\text { Information }\end{array}$ & $8 、 9$ \\
\hline & $\begin{array}{l}\text { Understanding } \\
\text { Information }\end{array}$ & $\begin{array}{c}\text { Resource } \\
\text { Management }\end{array}$ & 10、 11 \\
\hline \multirow[t]{3}{*}{$\begin{array}{l}\text { Application And Innovation Of } \\
\text { Digital Learning Resources }\end{array}$} & $\begin{array}{l}\text { Autonomous } \\
\text { Learning }\end{array}$ & $\begin{array}{l}\text { Collaborative } \\
\text { Learning }\end{array}$ & 12、13 \\
\hline & Digital Learning & Innovation Ability & $14 、 15$ \\
\hline & Teaching Methods & Self-Management & $16 、 17$ \\
\hline
\end{tabular}

\subsection{Data collection and analysis}

The respondents of this questionnaire are senior high school students of S Middle School in Anhui Province, China. Questionnaires were distributed randomly in two classes of S high 
school, and 80 valid questionnaires were obtained. The results of the collected questionnaire data are analysed as follows. It can be seen from Table 2 that the reliability coefficients of the research data are all greater than 0.7 .

Table 2. Questionnaire reliability analysis.

Cronbach reliability analysis

\begin{tabular}{ccc}
\hline The number & Sample size & Cronbach $\alpha$ coefficient \\
\hline 17 & 80 & 0.711 \\
\hline
\end{tabular}

\section{Analysis of questionnaire data}

\subsection{Adaptation and management of digital environment}

The results show that $66.25 \%$ of senior high school students have been in touch with computers since primary school and have been in touch for a long time. They generally have basic knowledge of computers and have mastered basic skills related to computers. According to the results of the survey "Where do you Usually have a computer", senior high school students are overwhelmingly exposed to computers at home and at school, accounting for 67.5 percent and 72.5 percent of those surveyed respectively. Therefore, in the process of information technology teaching, we should pay attention to the use of digital environment by schools, families and society. The results of the answer "the purpose of using computers" show that the main purpose of using computers for senior high school students includes entertainment and searching for information, accounting for $71.25 \%$. In addition, more than $50 \%$ of students use computers to download files, and more than $40 \%$ use computers to edit documents, learn software and learn courses. Most students can use computers to search for information, learn lessons, download files and other learningrelated activities. At the same time, these capabilities need to be strengthened.

\subsection{Acquisition and utilization of digital learning resources}

In terms of "ability to use Internet technology", "ability to assess and use digital tools", "ability to search for information", "ability to process information" and "ability to understand information", students over 60 rated themselves as "fair" or "good". At the same time, more than half of the students think that they can use effective methods to manage the learning materials, $37.5 \%$ of the students think that their ability is average, only $5 \%$ of the students in the question "can use effective methods to manage the learning materials" negative attitude.

In general, most high school students can reasonably evaluate and use digital learning resources and tools, but a small number of high school students have some difficulties in this aspect. This requires teachers to carry out targeted guidance in information technology classroom teaching.

\subsection{Application of digital learning methods}

More than $70 \%$ of the students think their independent learning and collaborative learning ability belongs to the "average" or "good" level, the students think their learning ability is poor is relatively small. More than $40 \%$ of the students think their digital learning ability is average, $32.5 \%$ of the students think their digital learning ability is good, and $7.5 \%$ and $5 \%$ of the students think their digital learning ability is poor and very poor, accounting for a 
relatively small number. In terms of the ability to form innovative works, students' answers were different from those of the previous abilities. The number of students who chose "better" was more than the number who chose "average", indicating that high school students have their own ideas on innovation and can form innovative works well. Teachers need to give them enough opportunities, as well as timely guidance and effective evaluation of their work.

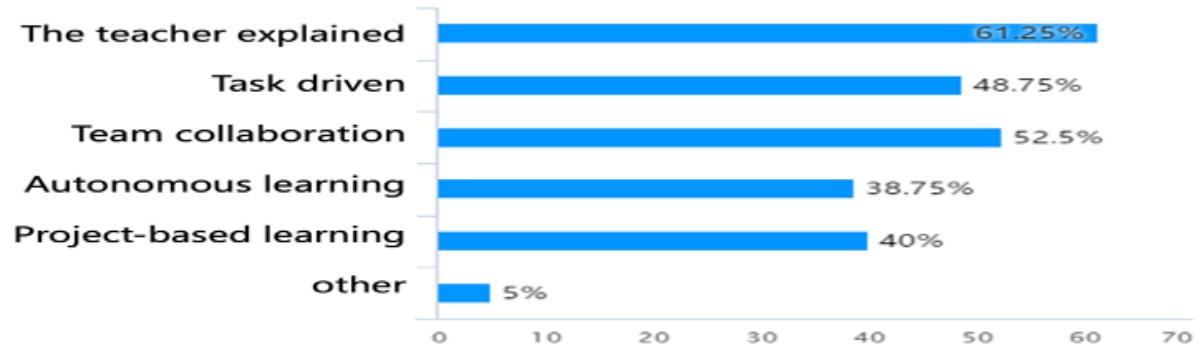

Fig. 1. The teaching methods that students want teachers to adopt.

As is shown in Figure 1, most of the students expect the teacher to adopt the teaching method of "the teacher explained", "task driven" and "team collaboration". There is also some students hope that teachers can use the teaching method of "autonomous learning" and "project-based learning”. In the "other" option, students also suggested that they would like to learn by watching videos.

Table 3. Students self-manage data.

\begin{tabular}{c|c}
\hline Options & The average score \\
\hline Task management & 4.13 \\
\hline Time management & 3.19 \\
\hline Partnership management & 2.69 \\
\hline
\end{tabular}

Table 3 shows that the average score for task management was 4.13, time management was 3.19, and partner management was 2.69. At present, the task management ability of senior high school students is strong, but the partner management ability needs to be improved.

\subsection{Main Problems}

According to the analysis of the results of the three dimensions of senior high school students' "adaptation to digital environment", "collection and management of digital learning resources", and "application and innovation of digital learning resources", it can be found that there are currently the following problems in senior high school students' "digital learning and innovation" literacy.

\subsubsection{Literacy awareness}

Students generally have a certain understanding of the literacy of "digital learning and innovation", but their understanding level is not deep. Most students can recognize the importance of this quality, but do not know what it means and how to start improving it. In the past, students in the information technology courses are mostly passive, and their 
autonomy is not strong, and their cooperation ability is not enough. These make it difficult for learners to develop their own habits of independent learning. Moreover, the time for students to learn literacy is not long, and the infiltration of teachers in the course teaching also needs to be strengthened. However, with the deepening of curriculum reform, this phenomenon is changing.

\subsubsection{Literacy level}

The majority of students have a low level of digital learning and innovation. According to the questionnaire results, the level of most students has not reached the ideal state, in the cultivation of a great degree of efforts. As a result of the long-term "digital learning" habit and some ways of thinking affected, learning is passive, cooperation ability is not strong, innovation ability needs to be improved and so on, showing the overall level of literacy is not good.

\section{Strategies for high school students to achieve "digital learning and innovation" literacy}

$\mathrm{Li}$ believes that there are ways to cultivate core literacy, which can be achieved by adopting appropriate teaching methods, selecting vivid learning materials and mobilizing students' subjective efforts [10]. For high school information technology education, it is imperative to cultivate students' digital learning ability [11]. The accomplishment of "digital learning and innovation" in high school students is closely related to the teaching of information technology course [10]. The current authoritative definition of "digital learning and innovation" literacy in China should be the "Information Technology Curriculum Standard for General High School". According to its meaning and representation, the ability to adapt to the digital learning environment is the premise for high school students to achieve the core accomplishment of this discipline, the ability to collect and manage digital learning resources is the core of this accomplishment, and the ability to apply and innovate digital learning resources is the key to achieve this accomplishment. Therefore, these aspects need to be integrated into the strategy to achieve "digital learning and innovation" literacy.

Starting with the basic elements and links of classroom teaching, Yu puts forward four basic elements of effective classroom teaching: situation and problem; Reading and thinking; Teacher-student interaction and teacher guidance; Practice and feedback [12]. Xu elaborated strategies for cultivating students' quality of "digital learning and innovation" in the implementation of high school information technology courses from three aspects of "digital environment", "digital learning" and "digital innovation" [13]. Based on their viewpoints, this study proposes the following teaching strategies. Starting from the teaching setting of information technology courses and combining the connotation and performance of "digital learning and innovation" literacy, this study proposes strategies to realize "digital learning and innovation" literacy of senior high school students, as shown in Figure 2. It mainly includes: the creation of digital situation, the independent development of digital resources, the cooperative innovation of digital resources and the evaluation and reflection of digital tools. Through a series of links such as experience, participation, cooperation, innovative practice and reflection in the environment of information technology course evaluation, students gradually improve their ability to adapt to the digital environment, the ability to collect and manage digital learning resources and the ability to apply and innovate digital learning resources [14]. 


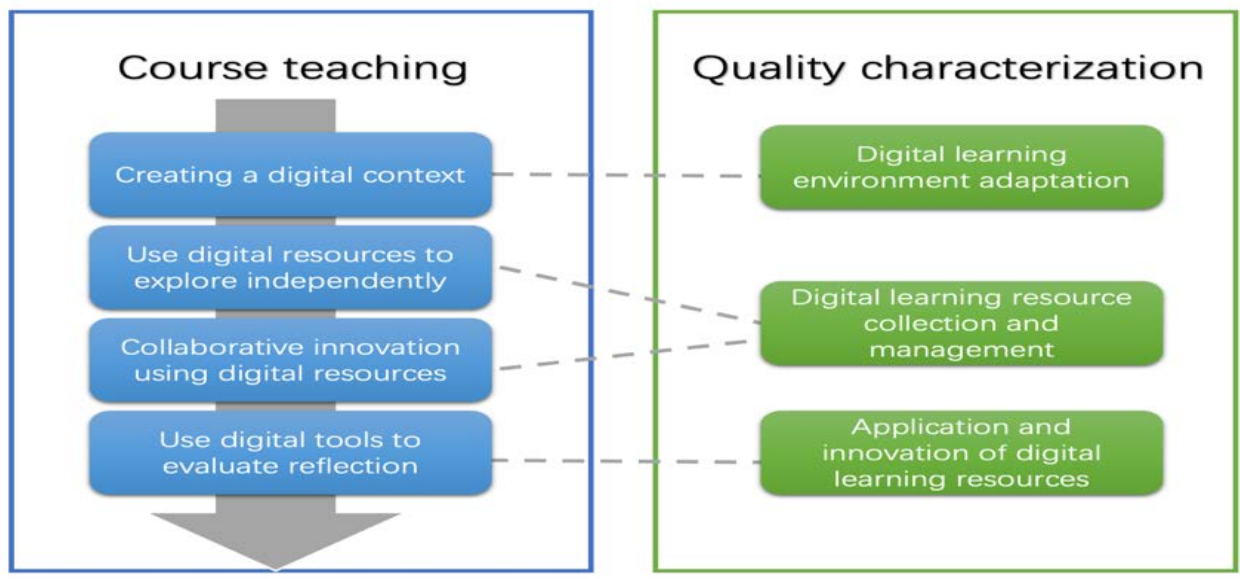

Fig. 2. Strategies for high school students to achieve "digital learning and innovation" literacy.

\subsection{Create digital context}

Professor Yang believes that in order to cultivate students' awareness of digital learning and innovation through high school its classes, teachers should guide students to solve problems with digital awareness [15]. In teaching design, introduction is a common method, which is applied to information technology course teaching, combined with the digital environment, to create digital situation, help students quickly adapt to the learning conditions in the digital classroom, into a good learning state. Therefore, at the beginning of the course, teachers need to create an appropriate digital environment to help arouse students' digital awareness.

\subsection{Independent exploration using digital resources}

In the process of digital learning, teachers can lead students to create digital works in the process of solving practical problems with digital tools and resources [16]. After students successfully adapt to the digital environment through the introduction of digital situation, they need to acquire and apply the digital resources. In this digital age, the types and types of learning resources are more and more abundant, among which, digital learning resources have become the focus and hotspot of current research. The effective use of these resources is also a necessary ability for high school students to achieve the accomplishment of "digital learning and innovation".

\subsection{Collaborative innovation using digital resources}

In classroom teaching, when organizing students to complete project activities, teachers should guide students to use digital tools to solve problems, guide students to carry out group cooperation and sharing, so that students can shift from the simple learning of knowledge and skills to the development of problem-solving and the formation of innovative works [17]. After making use of digital learning resources for independent exploration, students can further use digital learning resources for cooperation and innovation. Students collaborate and produce ultimately innovative work. In the course of teaching, the teacher groups the students reasonably, assigns the group task of building websites, and provides the students with the corresponding digital resources, such as some 
excellent website cases, information integration tools and software, picture material websites, etc., to assist the students in cooperative innovative learning activities.

\subsection{Use digital tools to evaluate reflection}

The use of digital tools for evaluation has more obvious advantages. Students can check anyone's works online and compare and evaluate their own learning by observing others' works. In the process of evaluating others, they can construct knowledge again and help themselves grow [18]. After the end of independent inquiry and cooperative innovation activities, the course teaching comes to an end. Teachers can use tools such as electronic portfolio to make comprehensive evaluation of students' learning situation, and can also use some digital tools to allow students to conduct mutual evaluation. To judge the students' information technology subject core literacy cultivation as the direct target, the evaluation method on learning results and learning process, give attention to two or more things in evaluation standard to both ability and foundation, according to the evaluation of the requirements, curriculum information technology subject core description of quality and grade level, select the appropriate evaluation content, Reasonable evaluation standards and feasible evaluation methods should be established, and effective core literacy test questions should be ordered [19].

\section{Conclusions}

Based on the quality representation of "digital learning and innovation" of high school students (adapting to the digital learning environment, collecting and managing digital learning resources, and applying and innovating digital learning resources), this study designed a questionnaire to investigate the status quo of "digital learning and innovation literacy" of middle school students. It was found that middle school students generally have a certain understanding of "digital learning and innovation" quality, but their understanding of it is not deep. Most students' digital learning and innovation literacy level is not good. Combined with the results of the questionnaire survey, teaching strategies are proposed to achieve this accomplishment, including: create digital context; independent exploration using digital resources; collaborative innovation using digital resources; use digital tools to evaluate reflection. Assist teachers to cultivate talents with "digital learning and innovation" quality in teaching.

\section{References}

1. Jiaqi Pan \& Junqiang Liu.(2019). "Digital Learning and Innovation" literacy interpretation and teaching suggestions. The Chinese Journal of ICT in Education (06), 1-4. doi:CNKI:SUN:JYXX.0.2019-06-001. (in Chinese)

2. Lin, M. H., \& Chen, H. G. (2017). A study of the effects of digital learning on learning motivation and learning outcome. Eurasia Journal of Mathematics, Science and Technology Education, 13(7), 3553-3564.

3. Xiaozhe Yang, \& Youqun Ren. (2017). Value Pursuit of Information Technology subject in Senior High school: Digital learning and innovation. China Educational Technology, (1), 21-26.(in Chinese)

4. Minxuan Chen, \& Ning Zhang. (2019). Design of learning activities based on core literacy of Information Technology subject in senior High school. China Educational Technology, (1), 87-93. (in Chinese) 
5. Francis, N., \& Santhakumar, A. B. (2020). Current trends in digital learning and innovation. In Theoretical and Practical Approaches to Innovation in Higher Education (pp. 1-16). IGI Global.

6. Liu, Y., Wei, X., \& Li, Z. (2019, December). Improving Design and Creative Ability of High School Students through Project Based Learning. In 2019 International Joint Conference on Information, Media and Engineering (IJCIME) (pp. 338-341). IEEE.

7. Lankester, A., Hughes, H., \& Foth, M. (2018). Mapping a connected learning ecology to foster digital participation in regional communities. In Digital Participation through Social Living Labs (pp. 141-171). Chandos Publishing.

8. Yueguang Xie, Xin Yang, \& Haidong Fu. (2017). The description and classification of senior High School Students' Core literacy in information Technology. China Educational Technology, (5), 8-14. (in Chinese)

9. Ministry of Education, People's Republic of China. General High School Information Technology Curriculum Standard (2017 edition)[M]. Beijing: People's Education Press, 2017.

10. Weiming Li. (2017). The Cultivation of core quality in the Teaching of Information Technology in senior High School. China Educational Technology, (5), 26-29. (in Chinese)

11. Xiaolin Gu, \& Yanhong Liao. (2020). Optimization strategy of digital learning in high school Information Technology education. China Information Technology Education. (in Chinese)

12. Wensen Yu.(2007).On Basic Essential Factors of Effective Classroom Learning. Research in Educational Development(Z2),38-42. doi:CNKI:SUN:SHGJ.0.2007-Z2015. (in Chinese)

13. Yuemei Xu.(2020). Research on implementation strategy of High school Information Technology digital Learning and Innovation literacy Cultivation. Educational Information Technology (Z2), 118-120. doi:CNKI:SUN:JYUX.0.2020-Z2-041. (in Chinese)

14. Yin Li. (2019). An example to discuss the implementation of core literacy in information technology teaching. China Information Technology Education,.(10):4344.(in Chinese)

15. Sunxi Yang.(2020). Digital Learning and Innovation Literacy cultivation in Information Technology Course. Journal of Fujian Computer (03),54-55. doi:10.16707/j.cnki.fjpc.2020.03.016. (in Chinese)

16. Pengpeng Wu.(2021). Practice of teacher-led digital learning and innovation literacy cultivation. China Information Technology Education(04),54-56. doi:CNKI:SUN:NETT.0.2021-04-021. (in Chinese)

17. Wuyin Yu(2020). Cultivating "Digital Learning and Innovation" literacy based on project Learning -- A case study of "Wireless Internet" in high school. China Information Technology Education (17),43-45. doi:CNKI:SUN:NETT.0.2020-17-017.

18. Haifeng Zhong.(2019). Micro-course helps students skillfully, and Turnover promotes Innovation -- An example of digital learning and innovation based on information technology discipline platform. China Information Technology Education (18), 44-47. doi:CNKI:SUN:NETT.0.2019-18-017.

19. Guangde Xiao, Xiongying Wei, \& Ronghuai Huang. (2017). Suggestions on the Evaluation of High School Information Technology Curriculum oriented to subject Core Literacy. China Educational Technology, 1, 33-37. (in Chinese) 